\title{
BMJ
}

\section{Association between muscular strength and mortality in men: prospective cohort study}

\author{
Jonatan R Ruiz, research associate, ${ }^{1,2}$ Xuemei Sui, research associate, ${ }^{3}$ Felipe Lobelo, research associate, ${ }^{3}$ \\ James R Morrow Jr, professor, ${ }^{4}$ Allen W Jackson, professor, ${ }^{4}$ Michael Sjöström, associate professor, ${ }^{1}$ \\ Steven N Blair, professor ${ }^{3,4}$
}

\begin{abstract}
${ }^{1}$ Department of Biosciences and Nutrition at NOVUM, Unit for Preventive Nutrition, Karolinska Institutet, Huddinge, Sweden

${ }^{2}$ Department of Physiology, School of Medicine, University of Granada, Spain

${ }^{3}$ Department of Exercise Science Arnold School of Public Health, University of South Carolina,

Columbia, SC, USA

${ }^{4}$ Department of Kinesiology, Health Promotion, and Recreation, University of North Texas, Denton, TX, USA
\end{abstract}

Correspondence to: J R Ruiz ruizj@ugr.es

Cite this as: BMJ 2008;337:a439 doi:10.1136/bmj.a439

\section{ABSTRACT}

Objective To examine prospectively the association between muscular strength and mortality from all causes, cardiovascular disease, and cancer in men.

Design Prospective cohort study.

Setting Aerobics centre longitudinal study.

Participants 8762 men aged 20-80.

Main outcome measures All cause mortality up to 31 December 2003; muscular strength, quantified by combining one repetition maximal measures for leg and bench presses and further categorised as age specific thirds of the combined strength variable; and cardiorespiratory fitness assessed by a maximal exercise test on a treadmill.

Results During an average follow-up of 18.9 years, 503 deaths occurred (145 cardiovascular disease, 199 cancer). Age adjusted death rates per 10000 person years across incremental thirds of muscular strength were 38.9, 25.9, and 26.6 for all causes; $12.1,7.6$, and 6.6 for cardiovascular disease; and 6.1, 4.9, and 4.2 for cancer (all P<0.01 for linear trend). After adjusting for age, physical activity, smoking, alcohol intake, body mass index, baseline medical conditions, and family history of cardiovascular disease, hazard ratios across incremental thirds of muscular strength for all cause mortality were 1.0 (referent), 0.72 (95\% confidence interval 0.58 to 0.90 ), and 0.77 (0.62 to 0.96); for death from cardiovascular disease were 1.0 (referent), 0.74 (0.50 to 1.10), and 0.71 (0.47 to 1.07); and for death from cancer were 1.0 (referent), 0.72 ( 0.51 to 1.00 ), and 0.68 (0.48 to 0.97 ). The pattern of the association between muscular strength and death from all causes and cancer persisted after further adjustment for cardiorespiratory fitness; however, the association between muscular strength and death from cardiovascular disease was attenuated after further adjustment for cardiorespiratory fitness.

Conclusion Muscular strength is inversely and independently associated with death from all causes and cancer in men, even after adjusting for cardiorespiratory fitness and other potential confounders.

\section{INTRODUCTION}

The role of muscular strength in the performance of activities of daily living and exercise, as well as in the prevention of chronic disease, is increasingly being recognised. ${ }^{12}$ Resistance exercise training increases muscular strength and is currently prescribed by major health organisations for improving health and fitness. ${ }^{3-6}$ Likewise, cardiorespiratory fitness provides strong and independent prognostic information about the overall risk of illness and death in adults across a broad spectrum of ages. ${ }^{7-13}$ This applies to apparently healthy people and to those with diabetes mellitus, hypertension, metabolic syndrome, and several types of cancer. ${ }^{14}$

Several prospective studies have shown that muscular strength is inversely associated with all cause mortality. ${ }^{15-27}$ All but two of these studies ${ }^{1826}$ assessed strength through a handgrip test, which involves relatively small muscle groups. In addition, most previous studies were short term follow-ups (4-6 years) $)^{15-1727}$ or included only older adults ( $\geq 65$ years). ${ }^{1720222326}$ The shorter term studies could have a problem with reverse causation, in that muscle weakness could be due to poor health. Moreover, it is unclear whether muscular strength is related to mortality in adults younger than 65 .

Preliminary analyses in the aerobics centre longitudinal study (ACLS) showed an inverse association between a standardised measure of muscular strength and all cause mortality after controlling for several potential confounders, including cardiorespiratory fitness. ${ }^{28}$ We regarded this early report as suggestive because it included a small number of deaths and combined men and women in the analyses, which prevented a thorough investigation of disease specific and sex specific mortality risks. The present study extends our previous analyses and focuses on the importance of muscular strength as a predictor of death from all causes, cardiovascular disease, and cancer in a large cohort of men. We also examined the combined association of muscular strength and cardiorespiratory fitness with mortality risk. We hypothesised that men with higher levels of muscular strength would have lower rates of mortality than those with lower levels of muscular strength.

\section{METHODS}

Between 1980 and 1989, 10265 men received a comprehensive medical examination and muscular 
strength tests at the Cooper Clinic in Dallas, Texas, United States, and were enrolled in the aerobics centre longitudinal study. Participants came to the clinic for periodic preventive health examinations and for counselling on diet, exercise, and other lifestyle factors associated with an increased risk of chronic disease. Participants thus were volunteers, were not paid, and were not recruited to the study as would be the case for a clinical trial. Many were sent by their employers for the examination, some were referred by their doctors, and others were self referred. The men in the analyses reported here were similar to the overall cohort of the study, with only minor differences in some clinical variables. For example, they were within $1 \mathrm{~mm} \mathrm{Hg}$ for systolic and diastolic blood pressures, had virtually identical total cholesterol levels, high density lipoprotein cholesterol levels, and body mass index (data not shown). The death rate for the subgroup of men in this analysis is not significantly different from the overall cohort adjusted for age, risk factor, health status, and family history.

Participants performed a maximal graded treadmill test to assess their cardiorespiratory fitness. They were excluded from the present study if they were younger than 20 or older than $90(n=91)$; they failed to achieve at least $85 \%$ of aged predicted maximal heart rate during the treadmill test $(\mathrm{n}=635)$; they had an abnormal resting or exercise electrocardiogram ${ }^{29}(\mathrm{n}=550)$; they reported a history of myocardial infarction $(\mathrm{n}=48)$, stroke $(\mathrm{n}=6)$, or cancer $(\mathrm{n}=52)$; or they were underweight (body mass index $<18.5 \mathrm{~kg} / \mathrm{m} 2 ; \mathrm{n}=121)$. These criteria resulted in 8762 men aged 20-82, who were followed up from the date of the baseline examination until the date of death or 31 December 2003. Mortality surveillance was by the National Death Index, which has been shown to be an accurate method of ascertaining deaths in observational studies, with high sensitivity $(96 \%)$ and specificity $(100 \%))^{30}$

Participants were predominantly white, well educated, and belonged to the middle and upper socioeconomic strata. Participants provided written informed consent to take part in the follow-up.

\section{Clinical examination}

The clinical examination, as well as measures of muscular strength and cardiorespiratory fitness, are described elsewhere. ${ }^{8132}$ Briefly, the baseline examination was completed subsequent to an overnight fast of at least 12 hours and included a physical examination and an array of clinical measurements. Body mass index was computed from height and weight measured with a standard clinical scale and stadiometer. Systolic and diastolic blood pressure were recorded at rest, as the first and fifth Korotkof sounds, using standard auscultation methods. ${ }^{33}$ Hypertension was defined as a systolic blood pressure of $140 \mathrm{~mm} \mathrm{Hg}$ or more, a diastolic blood pressure of $90 \mathrm{~mm} \mathrm{Hg}$ or more, or previous doctor diagnosed hypertension. Concentrations of total and high density lipoprotein cholesterol, triglycerides, and glucose were measured using automated techniques in accordance with the standards of the Centers for Disease Control and Prevention lipid standardisation programme. Diabetes mellitus was defined as a fasting plasma glucose concentration of $7 \mathrm{mmol} / \mathrm{l}$ or more, previous doctor diagnosis, or use of insulin or other hypoglycaemic drugs. Hypercholesterolaemia was defined as a total cholesterol concentration of $6.2 \mathrm{mmol} / \mathrm{l}$ or more. Participants completed a questionnaire on medical history, which included a personal history of myocardial infarction, stroke, hypertension, diabetes, or cancer; a family history of cardiovascular disease; a family history of cancer; smoking status; alcohol intake; and physical activity (sedentary or active). Sedentary was defined as reporting no physical activity during leisure time in the three months before the examination.

We assessed muscular strength in the upper and lower body using a standardised strength testing protocol of variable resistance weight machines (Universal Equipment, Cedar Rapids, IA, USA) ${ }^{3132}$ Upper body strength was assessed with a one repetition maximum supine bench press, and lower body strength was assessed with a one repetition maximum seated leg press. Initial loads were $70 \%$ of body weight for the bench press and $100 \%$ for the leg press. After a brief rest period, we added increments of $2.27 \mathrm{~kg}$ to $4.54 \mathrm{~kg}$ until maximal effort was achieved for each lift, usually after five or fewer trials. Participants were able to lift the initial load at least one time. They were instructed on proper breathing and lifting form for each movement. The intraclass correlation coefficient for one repetition maximum bench press and leg press was 0.90 and 0.83 , respectively, in a subgroup of $246 \mathrm{men}$ who underwent two muscular strength assessments within one year. ${ }^{31}$

We computed a score for muscular strength by combining the standardised values of bench and leg presses. Each of these variables was standardised using the formula: standardised value $=($ value - mean $) /$ standard deviation. We calculated the score separately for each age group (20-29, 30-39, 40-49, 50-59, and $\geq 60)$. The score for muscular strength was calculated as the mean of the two standardised scores (bench and leg presses). For analysis we used thirds of the age specific composite strength score.

We assessed cardiorespiratory fitness by a maximal treadmill test using a modified Balke protocol. ${ }^{834}$ Participants were encouraged to give maximal effort, and the test was stopped when participants reached volitional exhaustion or the doctor intervened for medical reasons. Participants were encouraged not to hold on to the handrails. The mean percentage of age predicted maximal heart rate (220-age) achieved during exercise was 101.6 (SD 6.2), indicating that most participants achieved maximal effort. Exercise duration using this protocol is highly correlated with measured maximal oxygen uptake $(\mathrm{r}=0.92){ }^{35} \mathrm{We}$ estimated maximal metabolic equivalents (1 maximal metabolic equivalent $=3.5 \mathrm{ml}$ oxygen uptake $/ \mathrm{kg} / \mathrm{min}$ ) from the final treadmill speed and grade. ${ }^{36} \mathrm{We}$ dichotomised cardiorespiratory fitness as unfit (low) and fit (high) corresponding to the lower $20 \%$ and the 
upper $80 \%$, respectively, of the age specific distribution of treadmill exercise duration in the overall population of the aerobics centre longitudinal study. ${ }^{737-41}$ This approach was used in the current analysis to maintain consistency with our other reports and because we have found that low cardiorespiratory fitness, defined in this way, is a strong and independent predictor of mortality.

\section{Mortality surveillance}

We computed person years of exposure as the sum of follow-up time among decedents and survivors. The National Death Index was the primary data source for mortality surveillance, augmented with death certificates. The underlying cause of death was determined from the index or by a nosologist's review of official death certificates obtained from the department of vital records in the decedent's state of residence. Death from cardiovascular disease was defined by ICD-9 (international classification of diseases, ninth revision) codes
390 to 449.9 before 1999 and ICD-10 codes I00 to I78 during 1999-2003. Death from cancer was defined by ICD-9 codes 140 to 208 and ICD-10 codes C00 to C97.

\section{Statistical analysis}

We calculated the baseline characteristics of the study population by vital status and by thirds of muscular strength. Differences in covariates were tested using Student $t$ tests, $\chi^{2}$ tests, and $\mathrm{F}$ tests. We used Cox proportional hazards regression to estimate hazard ratios, 95\% confidence intervals, and mortality rates (deaths per 10000 person years of follow-up), according to exposure categories. We adjusted multivariable analyses for age in model 1 , and in model 2 for age, physical activity (sedentary or active), smoking (current smoker or not), alcohol intake ( $\geq 5$ drinks a week or not), body mass index, baseline medical conditions (presence or not of hypertension, diabetes, or hypercholesterolaemia), and family history of cardiovascular

Table 1 | Baseline characteristics of participants in aerobics centre longitudinal study, 1980-2003, according to vital status and by thirds of muscular strength. Values are means (standard deviations) unless stated otherwise

\begin{tabular}{|c|c|c|c|c|c|c|c|c|}
\hline \multirow[b]{2}{*}{ Characteristic } & \multirow[b]{2}{*}{$\begin{array}{c}\text { All } \\
(n=8762)\end{array}$} & \multicolumn{3}{|c|}{ Vital status } & \multicolumn{4}{|c|}{ Muscular strength (thirds) } \\
\hline & & $\begin{array}{l}\text { Survivors } \\
(n=8259)\end{array}$ & $\begin{array}{l}\text { Decedents } \\
(n=503)\end{array}$ & $\begin{array}{c}P \\
\text { value* }\end{array}$ & $\begin{array}{l}\text { Lower } \\
(n=2920)\end{array}$ & $\begin{array}{l}\text { Middle } \\
(n=2919)\end{array}$ & $\begin{array}{c}\text { Upper } \\
(n=2923)\end{array}$ & $\begin{array}{l}\text { P for linear } \\
\text { trend }\end{array}$ \\
\hline Age (years) & $42.3(9.3)$ & $41.9(9.1)$ & $49.1(10.8)$ & $<0.001$ & $42.8(9.3)$ & $42.3(9.3)$ & $41.8(9.5)$ & $<0.001$ \\
\hline Body mass index $\left(\mathrm{kg} / \mathrm{m}^{2}\right)$ & $25.9(3.4)$ & $25.8(3.4)$ & $26.3(3.7)$ & 0.002 & $27.0(4.0)$ & $25.6(3.0)$ & $25.0(2.7)$ & $<0.001$ \\
\hline Maximal metabolic equivalents $\dagger$ & $12.5(2.5)$ & $12.6(2.5)$ & $11.4(2.5)$ & $<0.001$ & $11.5(2.3)$ & $12.6(2.3)$ & $13.5(2.4)$ & $<0.001$ \\
\hline Treadmill time (minutes) & $19.8(4.9)$ & $19.9(4.8)$ & $17.5(5.2)$ & $<0.001$ & $17.8(4.7)$ & $19.9(4.6)$ & $21.7(4.5)$ & $<0.001$ \\
\hline \multicolumn{9}{|l|}{ Upper body strength: } \\
\hline $\mathrm{kg}$ & $72.0(17.4)$ & $72.3(17.4)$ & $66.4(17.2)$ & $<0.001$ & $62.1(12.1)$ & $70.1(12.6)$ & $83.8(19.1)$ & $<0.001$ \\
\hline $\mathrm{kg} / \mathrm{kg}$ of body weight & $0.9(0.2)$ & $0.9(0.2)$ & $0.8(0.2)$ & $<0.001$ & $0.7(0.1)$ & $0.9(0.1)$ & $1.1(0.3)$ & $<0.001$ \\
\hline \multicolumn{9}{|l|}{ Lower body strength: } \\
\hline $\mathrm{kg}$ & $\begin{array}{l}137.5 \\
(26.9)\end{array}$ & $\begin{array}{l}137.9 \\
(26.8)\end{array}$ & $\begin{array}{l}130.3 \\
(27.6)\end{array}$ & $<0.001$ & $\begin{array}{l}125.7 \\
(24.8)\end{array}$ & $\begin{array}{l}136.2 \\
(23.5)\end{array}$ & $\begin{array}{l}150.4 \\
(26.4)\end{array}$ & $<0.001$ \\
\hline $\mathrm{kg} / \mathrm{kg}$ of body weight & $1.7(0.3)$ & $1.7(0.3)$ & $1.6(0.3)$ & $<0.001$ & $1.4(0.2)$ & $1.7(0.2)$ & $1.9(0.3)$ & $<0.001$ \\
\hline Composite strength score & $\begin{array}{l}2.43 \times 10-8 \\
(0.91)\end{array}$ & $0.02(0.91)$ & $\begin{array}{l}-0.35 \\
(0.86)\end{array}$ & $<0.001$ & $\begin{array}{l}-0.77 \\
(0.44)\end{array}$ & $\begin{array}{l}-0.06 \\
(0.40)\end{array}$ & $0.83(0.92)$ & $<0.001$ \\
\hline \multicolumn{9}{|l|}{ Lipids levels (mmol/l): } \\
\hline Total cholesterol & $5.4(1.1)$ & $5.4(1.1)$ & $5.6(1.2)$ & 0.003 & $5.5(1.1)$ & $5.5(1.3)$ & $5.3(1.0)$ & $<0.001$ \\
\hline $\begin{array}{l}\text { High density lipoprotein } \\
\text { cholesterol }\end{array}$ & $1.2(0.3)$ & $1.2(0.3)$ & $1.2(0.3)$ & 0.16 & $1.2(0.3)$ & $1.2(0.3)$ & $1.2(0.3)$ & $<0.001$ \\
\hline Triglycerides & $1.5(1.2)$ & $1.4(1.2)$ & $1.7(1.3)$ & $<0.001$ & $1.6(1.2)$ & $1.5(1.4)$ & $1.3(0.9)$ & $<0.001$ \\
\hline Fasting blood glucose, $(\mathrm{mmol} / \mathrm{l})$ & $5.5(0.8)$ & $5.5(0.7)$ & $5.7(1.4)$ & $<0.001$ & $5.6(0.9)$ & $5.5(0.6)$ & $5.5(0.6)$ & $<0.001$ \\
\hline \multicolumn{9}{|l|}{ Blood pressure $(\mathrm{mm} \mathrm{Hg})$ : } \\
\hline Systolic & 119 (13) & $118(12)$ & $123(15)$ & $<.001$ & $120(12)$ & $118(12)$ & $118(13)$ & $<0.001$ \\
\hline Diastolic & $79(9)$ & $79(9)$ & $82(10)$ & $<.001$ & $80(9)$ & $79(9)$ & $79(9)$ & $<0.001$ \\
\hline No (\%) sedentary & $1753(20.1)$ & $1642(19.9)$ & $111(22.1)$ & 0.23 & $760(26.0)$ & $585(20.0)$ & $408(14.0)$ & $<0.001$ \\
\hline No (\%) of current smokers & $1345(15.4)$ & $1226(14.8)$ & $119(23.7)$ & $<.001$ & $504(17.3)$ & $466(16.0)$ & $375(12.8)$ & $<0.001$ \\
\hline $\begin{array}{l}\text { No (\%) with alcohol intake } \geq 5 \\
\text { drinks weekly }\end{array}$ & $4377(50.0)$ & $4101(49.7)$ & $276(54.9)$ & .02 & $1471(50.4)$ & $1452(49.7)$ & $1454(49.7)$ & 0.86 \\
\hline \multicolumn{9}{|l|}{$\begin{array}{l}\text { Baseline medical conditions } \\
\text { (No, \%): }\end{array}$} \\
\hline Diabetes mellitus & $198(2.3)$ & $165(2.0)$ & $33(6.6)$ & $<0.001$ & $93(3.2)$ & $49(1.7)$ & $56(1.9)$ & $<0.001$ \\
\hline Hypertension & $2136(24.4)$ & $1939(23.5)$ & $197(39.2)$ & $<0.001$ & $847(29.0)$ & $674(23.1)$ & $615(21.0)$ & $<0.001$ \\
\hline Hypercholesterolaemia & $1873(21.4)$ & $1734(21.0)$ & $139(27.6)$ & $<0.001$ & $681(23.3)$ & $635(21.8)$ & $557(19.1)$ & $<0.001$ \\
\hline $\begin{array}{l}\text { No (\%) with family history of } \\
\text { premature cardiovascular disease }\end{array}$ & $2548(29.1)$ & $2331(28.2)$ & $217(43.1)$ & $<0.001$ & $874(29.9)$ & $840(28.8)$ & $834(28.5)$ & 0.45 \\
\hline
\end{tabular}


Table 2 | Rates and hazard ratios for mortality in men from all causes, cardiovascular disease, and cancer by thirds of muscular strength

\begin{tabular}{|c|c|c|c|c|c|}
\hline \multirow[b]{2}{*}{ Mortality (third) } & \multirow[b]{2}{*}{ No of deaths } & \multirow{2}{*}{$\begin{array}{c}\text { Age adjusted rate per } 10 \\
000 \text { person years }\end{array}$} & \multicolumn{3}{|c|}{ Hazard ratio $(95 \% \mathrm{Cl})$} \\
\hline & & & Model 1* & Model $2 \dagger$ & Model $3 \ddagger$ \\
\hline \multicolumn{6}{|l|}{ All causes: } \\
\hline Lower & 214 & 38.9 & 1.00 (Referent) & 1.00 (Referent) & 1.00 (Referent) \\
\hline Middle & 143 & 25.9 & 0.66 (0.54 to 0.82$)$ & 0.72 (0.58 to 0.90$)$ & 0.74 (0.59 to 0.91$)$ \\
\hline Upper & 146 & 26.6 & $0.68(0.55$ to 0.84$)$ & 0.77 (0.62 to 0.96$)$ & 0.80 (0.64 to 0.996$)$ \\
\hline $\mathrm{P}$ for linear trend & & & $<0.001$ & 0.01 & 0.03 \\
\hline \multicolumn{6}{|c|}{ Cardiovascular disease: } \\
\hline Lower & 66 & 12.1 & 1.00 (Referent) & 1.00 (Referent) & 1.00 (Referent) \\
\hline Middle & 42 & 6.6 & 0.63 (0.43 to 0.93$)$ & 0.74 (0.50 to 1.10$)$ & 0.78 (0.52 to 1.16$)$ \\
\hline Upper & 37 & 7.6 & $0.55(0.37$ to 0.82$)$ & 0.71 (0.47 to 1.07$)$ & $0.78(0.51$ to 1.20$)$ \\
\hline $\mathrm{P}$ for linear trend & & & 0.003 & 0.09 & 0.22 \\
\hline \multicolumn{6}{|l|}{ Cancer: } \\
\hline Lower & 88 & 6.1 & 1.00 (Referent) & 1.00 (Referent) & 1.00 (Referent) \\
\hline Middle & 58 & 4.2 & 0.66 (0.47 to 0.92$)$ & $0.72(0.51$ to 1.00$)$ & 0.71 (0.50 to 0.996$)$ \\
\hline Upper & 53 & 4.9 & $0.60(0.43$ to 0.85$)$ & 0.68 (0.48 to 0.97$)$ & 0.67 (0.47 to 0.96$)$ \\
\hline$P$ for linear trend & & & 0.003 & 0.03 & 0.02 \\
\hline
\end{tabular}

*Adjusted for age.

†Adjusted for age, physical activity, current smoking, alcohol intake, body mass index, baseline medical conditions, and family history of cardiovascular disease.

$\ddagger$ Adjusted for age plus physical activity, current smoking, alcohol intake, body mass index, baseline medical conditions, family history of cardiovascular disease, and cardiorespiratory fitness.

disease. Additional analyses were done after further adjustment for cardiorespiratory fitness (model 3), entered as a continuous variable. A total of 2548 (29.1\%) participants reported a family history of cardiovascular disease. As none of the participants reported a family history of cancer, therefore we omitted this variable from the model.

Muscular strength and functional aerobic capacity decline steadily with age. ${ }^{42}$ To determine whether the association between muscular strength and mortality differed by age, we examined the association in younger men ( $<60$ years) and older men ( $\geq 60$ years). To determine whether the association between muscular strength and mortality varied by body weight, we examined the association within defined categories of body mass index for normal weight $\left(18.5-24.9 \mathrm{~kg} / \mathrm{m}^{2}\right)$ and overweight $\left(\geq 25 \mathrm{~kg} / \mathrm{m}^{2}\right)$. Finally, we examined the combined effects of muscular strength and cardiorespiratory fitness on all cause mortality. For this analysis we created six categories for combinations of strength and fitness on the basis of thirds of muscular strength and we dichotomised these in to fit groups and unfit groups. We compared the effect of each combination of strength and fitness status (low strength, unfit; middle strength, unfit; high strength, unfit; low strength, fit; middle strength, fit; high strength, fit) with the referent group (low strength, unfit). Cumulative hazard plots grouped by exposure suggested no appreciable violations of the proportional hazards assumption. Excluding deaths that occurred during the first two years of follow-up did not materially change the results. We calculated two sided $\mathrm{P}$ values and we considered those $<0.05$ as significant. Analyses were done using SAS statistical software, version 9.1 .

\section{RESULTS}

During an average follow-up of 18.9 years and 165251 person years of observation $503(5.7 \%)$ deaths occurred: $145(28.8 \%)$ from cardiovascular disease and $199(39.6 \%)$ from cancer. Table 1 shows the baseline characteristics of the participants on the basis of vital status and thirds of muscular strength. Muscular strength, as well as exercise duration and maximal metabolic equivalents, were significantly higher in survivors than in decedents. A direct gradient of treadmill test duration across thirds of muscular strength was observed. Age, body mass index, blood pressure, and levels of total cholesterol, triglycerides, and glucose were higher in decedents and in those with lower levels of muscular strength.

Table 2 shows age adjusted death rates and hazard ratios (model 1) for death from all causes, cardiovascular disease, and cancer; hazard ratios after further adjustment for smoking, alcohol intake, body mass index, baseline medical conditions, and family history of cardiovascular disease (model 2); and hazard ratios after additionally adjusting for cardiorespiratory fitness (model 3). All cause mortality rates were 1.50 (38.9/ 25.9) and $1.46(38.9 / 26.6)$ times greater for those in the lowest third of muscular strength than for those in the middle and upper thirds of muscular strength, respectively. The corresponding differences for death from cardiovascular disease were $1.83(12.1 / 6.6)$ and 1.59 $(12.1 / 7.6)$ times greater, and for death from cancer were $1.45(6.1 / 4.2)$ and $1.24(6.1 / 4.9)$ times greater. The age adjusted results of model 1 showed a notably declining risk of death from all causes, cardiovascular disease, and cancer across incremental thirds of muscular strength (all $\mathrm{P}<0.01$ for linear trend). After the additional adjustments (model 2), risks of death 

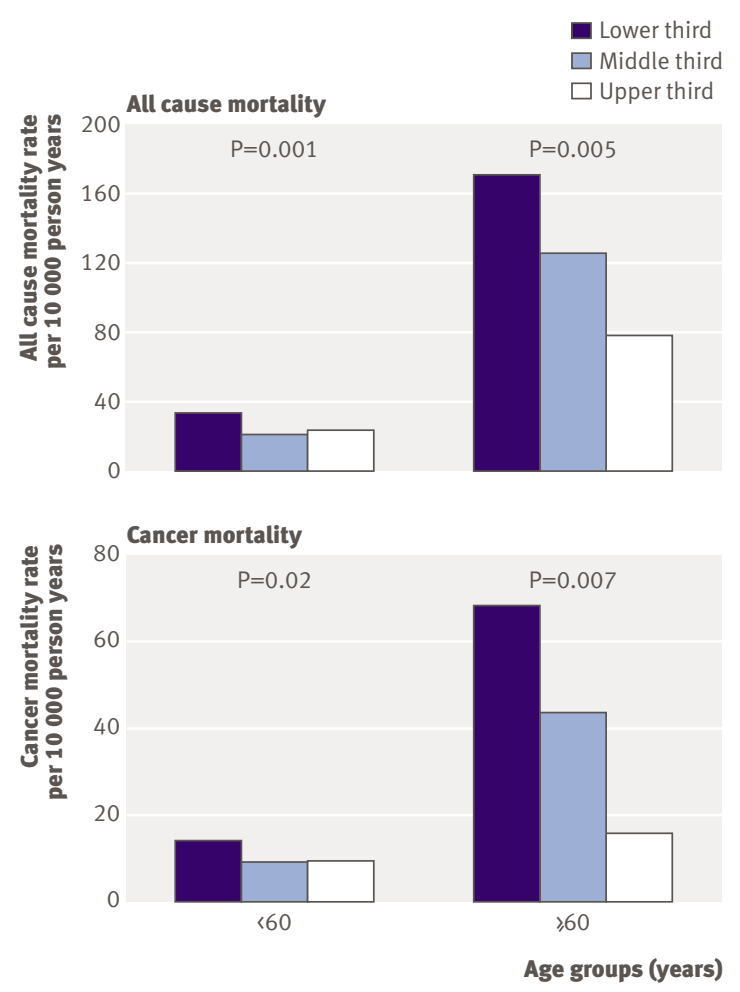

Fig 1 Age adjusted death rates per 10000 person years from all causes and cancer by thirds of muscular strength and age groups

from all causes and cancer remained progressively lower with higher levels of muscular strength (both $\mathrm{P}<0.05$ for linear trend), whereas the association between muscular strength and death from cardiovascular disease was attenuated $(\mathrm{P}=0.08$ for linear trend). The association between muscular strength and risks of death from all causes or cancer remained significant after further adjustment for cardiorespiratory fitness (both $\mathrm{P}<0.05$ for linear trend), whereas the association between muscular strength and risk of death from cardiovascular disease was no longer statistically significant once the analysis was further adjusted for cardiorespiratory fitness $(\mathrm{P}=0.23$ for linear trend).

Figure 1 shows the association between muscular strength and death from all causes or cancer in men aged $<60$ years $(\mathrm{n}=8397)$ and $\geq 60$ years $(\mathrm{n}=383)$ and figure 2 shows the association in men of normal weight $(\mathrm{n}=3890,44 \%)$ and overweight men $(\mathrm{n}=4782,56 \%)$. Strong statistical evidence existed of an interaction between muscular strength and age in predicting death from all causes $\left(\chi^{2}=10.46(\mathrm{df}=1), \mathrm{P}=0.001\right)$ and cancer $\left(\chi^{2}=6.49(\mathrm{df}=1), \mathrm{P}=0.01\right)$ but weak statistical evidence of an interaction between muscular strength and body mass index in predicting death from all causes $\left(\chi^{2}=1.71\right.$ $(\mathrm{df}=1), \mathrm{P}=0.19)$ and cancer $\left(\chi^{2}=1.62(\mathrm{df}=1), \mathrm{P}=0.20\right)$. A significant inverse gradient was found for death from all causes and cancer across incremental thirds of muscular strength within each age group (both $\mathrm{P}<0.05$ for linear trend). Across age strata, those in the lowest third of muscular strength had a 1.4-fold to 2.2-fold and 1.5- fold to 4.3-fold higher rates of mortality from all causes and cancer than those in the upper third of muscular strength. Muscular strength also was inversely associated with all cause mortality in men of normal weight and overweight men (both $\mathrm{P}<0.05$ for linear trend) and with cancer mortality in overweight men $(\mathrm{P}=0.03$ for linear trend; fig 2). Across incremental thirds of muscular strength, age adjusted total death rates per 10000 person years were $32.9,25.6$, and 20.7 in men of normal weight $(\mathrm{P}=0.009$ for linear trend) and 42.1, 26.2 , and 33.8 in overweight men $(\mathrm{P}=0.046$ for linear trend).

Figure 3 shows the age adjusted death rates for all causes across thirds of muscular strength and cardiorespiratory fitness categories (unfit and fit), which resulted in six groups for strength and cardiorespiratory fitness. The death rate in the unfit men with the lowest muscular strength was the highest among the six combination groups. The adjusted death rate per 10000 person years was inversely related to muscular strength within the fit cardiorespiratory fitness group ( $\mathrm{P}=0.008$ for linear trend), and inversely related to cardiorespiratory fitness within the lowest third $(\mathrm{P}=0.003)$ and middle third $(\mathrm{P}=0.03)$ of muscular strength.

\section{DISCUSSION}

Muscular strength was significantly and inversely associated with risk of death from all causes and cancer after controlling for potential confounders, including cardiorespiratory fitness. The inverse association was consistent in strata of age ( $<60$ and $\geq 60$ years) and body
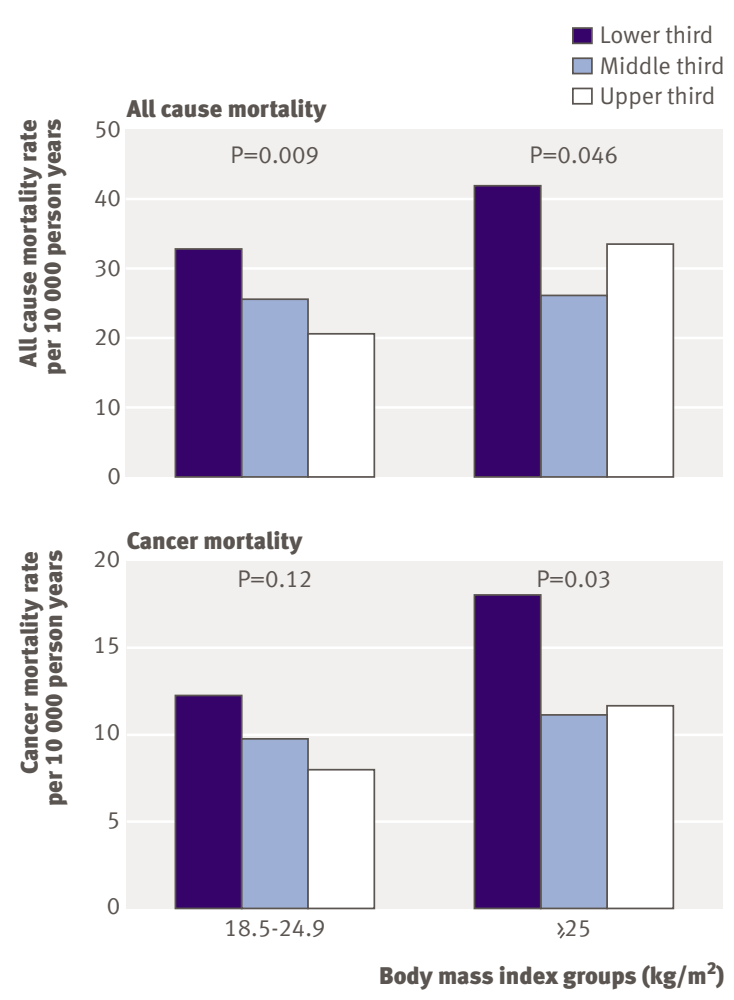

Fig 2 Age adjusted death rates per 10000 person years by thirds of muscular strength and body mass index groups 


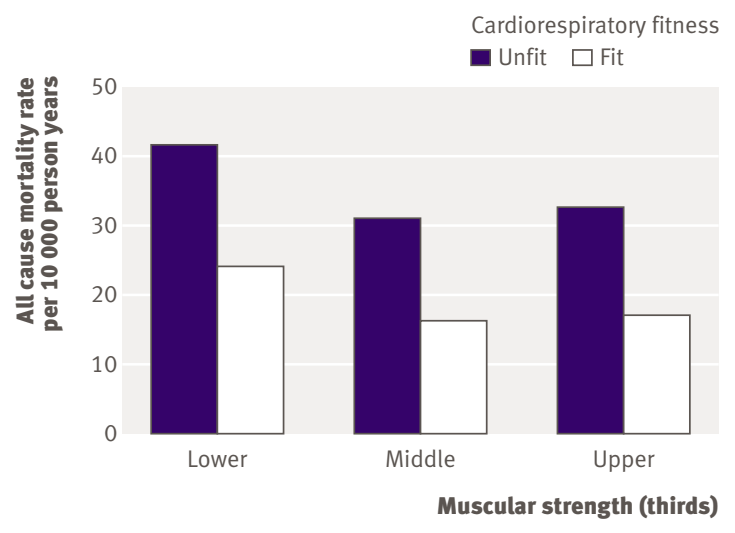

Fig 3 Number of men and age adjusted all cause death rates per 10000 person years according to thirds of muscular strength and cardiorespiratory fitness categories. Adjusted death rate was inversely related to muscular strength within fit cardiorespiratory category ( $\mathrm{P}=0.008$ for trend) but not within unfit category ( $\mathrm{P}=0.44$ for trend), and inversely related to cardiorespiratory fitness within lowest third $(P=0.003)$ and middle third $(P=0.03)$ for muscular strength but not within highest third $(\mathrm{P}=0.27)$

mass index $\left(18.5-24.9\right.$ and $\left.\geq 25 \mathrm{~kg} / \mathrm{m}^{2}\right)$. Muscular strength was significantly and inversely associated with risk of death from cardiovascular disease after controlling for age, yet the association was attenuated once other potential confounders were entered in the model and was not significant after further adjustment for cardiorespiratory fitness. The analysis on the combined effects of muscular strength and cardiorespiratory fitness with all cause mortality showed that the age adjusted death rate in men with high levels of both muscular strength and cardiorespiratory fitness was $60 \%$ lower $(\mathrm{P}<0.001)$ than the death rate in the group of unfit men with the lowest levels of muscular strength. These results highlight the importance of having at least moderate levels of both muscular strength and cardiorespiratory fitness to reduce risk of death from all causes and cancer in this population of men.

We investigated the association between standardised measures of upper and lower body muscular strength and disease specific risk of mortality in a large cohort of men with extensive follow-up. Muscular strength and cardiorespiratory fitness were moderately correlated (age adjusted partial $r=0.33$ ), suggesting that the association between muscular strength and risk of death from cancer works at least partially through different mechanisms than those associated with the protective effects of cardiorespiratory fitness. That the association between muscular strength and risk of death from cardiovascular disease was not significantly independent of cardiorespiratory fitness highlights the key role of cardiorespiratory fitness in the development of cardiovascular disease in men; however, their combined effects cannot be easily disentangled in an observational study. In this cohort the number of deaths from cardiovascular disease was lower than that from cancer (145 and 199, respectively). This may have reduced the statistical power to detect a significant independent association between muscular strength and risk of death from cardiovascular disease.

Apart from our preliminary analyses in the aerobics centre longitudinal study ${ }^{28}$ only one study has assessed the association between muscular strength and all cause mortality after adjusting for cardiorespiratory fitness and age, smoking status, and body mass index and found that handgrip strength and upper body strength (push-ups) were not significantly associated with risk of death from all causes. ${ }^{18} \mathrm{~A}$ significant inverse association between muscular strength (measured by handgrip strength) and risk of mortality has been reported in several other studies. ${ }^{15-1719-2527}$ The main limitation of this test is that the measurement is highly influenced by the grip span of the dynamometer and hand size. ${ }^{44-46}$ None of these previous studies standardised the grip span or assessed a second muscle group. Furthermore, hand grip uses a relatively small muscle group and is not well correlated with measures of overall muscular strength as determined by measurements of strength using large muscle groups. ${ }^{47}$ Assessing additional muscle groups may provide a better overall index of muscular strength, especially when measured in large muscle groups. Moreover, cardiorespiratory fitness was not measured in these studies, and we know that cardiorespiratory fitness is strongly associated with morbidity and mortality. ${ }^{7-1337-39}$

The apparent protective effect of muscular strength against risk of death might be due to muscular strength in itself, to muscle fibre type or configuration, or as a consequence of regular physical exercise, specifically resistance exercise. Muscle fibre type and configuration has a genetic component and influences strength, yet it is clear that resistance type physical activities are major determinants of muscular strength. ${ }^{58}$ We have previously reported a strong and positive association between the frequency of self reported resistance exercise and maximal muscular strength in men enrolled in the aerobics centre longitudinal studythat is, the higher the participation in resistance exercise the higher the muscular strength. ${ }^{32}$ This observation suggests that the measurements of muscular strength obtained in the present study provide an adequate representation of the resistance exercise habits in our cohort. Results from intervention studies indicate that resistance training enhances muscular strength and endurance, muscle mass, functional capacity, daily physical activity, risk profile for cardiovascular disease, and quality of life. ${ }^{5}$ These factors are well known predictors of higher risk of mortality. The benefits of resistance training are evident in men and women, young adults, and older people, in overweight and obese adults as well as in people of normal weight, and in people with or without disability, or with cardiovascular disease. ${ }^{5}$ We observed an inverse association between muscular strength and risk of death from all causes and cancer in older men ( $\geq 60$ years) and younger men $(<60$ years). This suggests that older men may also benefit from having higher levels of muscular strength. In older men, functional 
performance becomes more directly dependent on strength, as these men also experience age associated declines in muscle mass and consequently in muscular strength.

The observed association between muscular strength and risk of death from all causes or cancer was also independent of body weight. We showed an inverse association between muscular strength and risk of death from all causes and cancer in overweight and obese men, as well as between muscular strength and risk of all cause mortality in those of normal body weight. Body mass index may have a different meaning in those who have greater muscular strength. For example, leg press strength for a man weighing $60 \mathrm{~kg}$ would be expected to be lower than that for a man weighing $90 \mathrm{~kg}$. That is why we included body mass index in the multivariate analyses. Thus we not only controlled for the effect of weight but also height, which might have influenced the torque or force production. A high body mass index can result from a greater amount of fat or muscle. Yet in epidemiological studies most of the people with a higher body mass index also had higher fat levels.

Given that the prevalence of overweight and obesity exceeds $66 \%$ in the United States ${ }^{49}$ and that overweight and obese people are at a substantially higher risk of disability ${ }^{50}$ and death, ${ }^{5152}$ these results have important implications for public health. Exercise recommendations to prevent or treat obesity have focused mainly on aerobic activities, yet resistance exercise is an important complement for weight control, mainly as a result of the increases in metabolically active muscle mass. ${ }^{2}$ Under most circumstances, and especially during physical inactivity, resting energy expenditure is the largest component of total energy expenditure. The energy expenditure related to muscle metabolism is the only component of resting energy expenditure that might vary considerably. ${ }^{2}$ The resting metabolic requirements of splanchnic tissues, brain, and skin vary little under normal conditions, mainly because of their relatively constant mass and protein turnover rates. In contrast, large variations in muscle mass are possible, and the rate of muscle protein turnover (synthesis and breakdown) may vary as well. The synthesis and breakdown of muscle protein are principally responsible for the energy expenditure of resting muscle. In theory, every $10 \mathrm{~kg}$ difference in lean mass translates to a difference in energy expenditure of about $100 \mathrm{kcal}$ daily, assuming a constant rate of protein turnover. ${ }^{2}$ A difference in energy expenditure of about $100 \mathrm{kcal}$ daily translates to about $4.7 \mathrm{~kg}$ of fat mass yearly. Over a long period the maintenance of a large muscle mass and consequent muscle protein turnover can contribute to the prevention of obesity. Therefore it is reasonable to presume that when sustained over time, resistance exercise training should help to prevent or revert increases in body fat. ${ }^{5}$

\section{Strengths and limitations}

The results of the present study should be interpreted with caution. Generalisation of the findings may only apply to well educated white men of middle to upper socioeconomic status. Values for blood pressure and cholesterol levels, body weight, and cardiorespiratory fitness from participants in the aerobics centre longitudinal study were similar to those reported in two population based studies in North America. ${ }^{8}$ Moreover, there is no reason to believe that the benefits of muscular strength would be different in other ethnic or socioeconomic groups. Because of the limited sample of women, who contributed relatively few deaths to the main study, we were unable to perform a meaningful parallel analysis on women. Therefore women were not included in this substudy. No detailed information about drug use or diet was available, which may have biased the results through residual confounding. It seems unlikely, however, that these factors would account for all of the observed association between muscular strength and mortality. That none of the participants reported a family history of cancer might be a limitation of the main study owing to self selection bias. In fact, only $1.16 \%$ of men in the entire cohort of the aerobics centre longitudinal study reported a family history of cancer. Future studies should include such information whenever possible.

A major strength of this study was the inclusion of objective and standardised maximal tests for muscular strength (upper and lower body) and cardiorespiratory fitness using highly reliable measurement protocols in a large cohort of men with extensive follow-up. Undetected subclinical disease is always a concern in any observational study, but it is less likely to have occurred in our cohort because of the comprehensive physical examination and the clinical assessment completed by each participant. Moreover, participants were healthy enough to achieve at least $85 \%$ of aged predicted maximal heart rate during the treadmill test.

\section{Conclusions}

Muscular strength was independently associated with risk of death from all causes and cancer in men. These findings are valid for men of normal weight, those who are overweight, and younger or older men, and are valid even after adjusting for several potential confounders, including cardiorespiratory fitness. Muscular strength seems to add to the protective effect of cardiorespiratory fitness against the risk of death in men. Whether the association between muscular strength and risk of death from cardiovascular disease is independent of typical confounders as well as of cardiorespiratory fitness warrants further investigation.

Prospective studies among diverse populations and among women are needed to examine the independent and combined associations of muscular strength and cardiorespiratory fitness with disease specific mortality. It might be possible to reduce all cause mortality among men by promoting regular resistance training involving the major muscle groups of the upper and lower body two or three days a week. ${ }^{5}$ Resistance training should be a complement to rather than a replacement for aerobic exercise. The 


\section{WHAT IS ALREADY KNOWN ON THIS TOPIC}

Cardiorespiratory fitness provides strong and independent prognostic information about the overall risk of illness and death

Most prospective studies examining the association between muscular strength and death have had limitations

\section{WHAT THIS STUDY ADDS}

Muscular strength in major muscle groups is independently associated with death from all causes and cancer in men aged 20-82

These findings are valid for those who are of normal weight or overweight, younger or older, and even after adjusting for several potential confounders, including cardiorespiratory fitness

Muscular strength seems to add to the protective effect of cardiorespiratory fitness against the risk of death in men
8 Blair SN, Kohl HW 3rd, Paffenbarger RS Jr, Clark DG, Cooper KH, Gibbons LW. Physical fitness and all-cause mortality. A prospective study of healthy men and women. JAMA 1989;262:2395-401.

9 Myers J, Prakash M, Froelicher V, Do D, Partington S, Atwood JE. Exercise capacity and mortality among men referred for exercise testing. N Engl J Med 2002;346:793-801.

10 Mora S, Redberg RF, Cui Y, Whiteman MK, Flaws JA, Sharrett AR, et al. Ability of exercise testing to predict cardiovascular and all-cause death in asymptomatic women: a 20-year follow-up of the lipid research clinics prevalence study. JAMA 2003;290:1600-7.

11 Gulati M, Black HR, Shaw LJ, ArnsdorfMF, Merz CN, Lauer MS, et al. The prognostic value of a nomogram for exercise capacity in women. $N$ Engl J Med 2005;353:468-75.

12 Ekelund LG, Haskell WL, Johnson JL, Whaley FS, Criqui MH, Sheps DS. Physical fitness as a predictor of cardiovascular mortality in asymptomatic North American men. The lipid research clinics mortality follow-up study. N Engl J Med 1988;319:1379-84.

13 Sui X, LaMonte MJ, Laditka JN, Hardin JW, Chase N, Hooker SP, et al. Cardiorespiratory fitness and adiposity as mortality predictors in olde adults. JAMA 2007;298:2507-16.

14 LaMonte MJ, Blair SN. Physical activity, cardiorespiratory fitness, and adiposity: contributions to disease risk. Curr Opin Clin Nutr Metab Care 2006;9:540-6.

recommendation for moderate to vigorous physical activity and resistance training are supported by the current research owing to the reduction in risk of death from all causes and cancer associated with increased cardiorespiratory fitness or muscular strength. ${ }^{3-6}$

We thank the doctors and technicians at the Cooper Clinic who collected the baseline data and staff at the Cooper Institute for data entry and data management.

Contributors: All authors were involved in the concept and design of the study, the analysis and interpretation of data, drafting the manuscript, and critical revision of the manuscript for important intellectual content. They are guarantors. XS and SNB acquired the data. JRR, XS, FL, JRM, AWJJr, and SNB did the statistical analysis.

Funding: The aerobics centre longitudinal study was supported by the National Institutes of Health (grants AG06945, HL62508); the Spanish Ministry of Education (AP2003-2128, EX-2007-1124); the Margit and Folke Pehrzon Foundation; the European Union, in the framework of the public health programme (ALPHA project, 2006120); the American Heart Association predoctoral fellowship; and the American College of Sports Medicine Paffenbarger-Blair fund for epidemiological research on physical activity.

Competing interests: None declared.

Ethical approval: This study was approved by the Cooper Institute institutional review board.

Provenance and peer review: Not commissioned; externally peer reviewed.

1 Stump CS, Henriksen EJ, Wei Y, Sowers JR. The metabolic syndrome: role of skeletal muscle metabolism. Ann Med 2006;38:389-402.

2 Wolfe RR. The underappreciated role of muscle in health and disease. Am J Clin Nutr 2006;84:475-82.

3 Pollock ML, Franklin BA, Balady GJ, Chaitman BL, Fleg IL, Fletcher B, et al. AHA science advisory. Resistance exercise in individuals with and without cardiovascular disease: benefits, rationale, safety, and prescription: An advisory from the Committee on Exercise, Rehabilitation, and Prevention, Council on Clinical Cardiology, American Heart Association; position paper endorsed by the American College of Sports Medicine. Circulation 2000;101:828-33.

4 Kraemer WJ, Adams K, Cafarelli E, Dudley GA, Dooly C, Feigenbaum MS, et al. American College of Sports Medicine position stand. Progression models in resistance training for healthy adults. Med Sci Sports Exerc 2002:34:364-80.

5 Williams MA, Haskell WL, Ades PA, Amsterdam EA, Bittner V, Franklin BA, et al. Resistance exercise in individuals with and without cardiovascular disease: 2007 update: a scientific statement from the American Heart Association Council on Clinical Cardiology and Council on Nutrition, Physical Activity, and Metabolism. Circulation 2007;116:572-84.

6 Haskell WL, Lee IM, Pate RR, Powell KE, Blair SN, Franklin BA, et al. Physical activity and public health: updated recommendation for adults from the American College of Sports Medicine and the American Heart Association. Circulation 2007:116:1081-93.

7 Blair SN, Kohl HW 3rd, Barlow CE, Paffenbarger RS Jr, Gibbons LW, Macera CA. Changes in physical fitness and all-cause mortality. A prospective study of healthy and unhealthy men. JAMA 1995;273:1093-8

15 Phillips P. Grip strength, mental performance and nutritional status indicators of mortality risk among female geriatric patients. Age Ageing 1986;15:53-6.

16 Fujita Y, Nakamura Y, Hiraoka J, Kobayashi K, Sakata K, Nagai M, et al. Physical-strength tests and mortality among visitors to healthpromotion centers in Japan. J Clin Epidemiol 1995;48:1349-59.

17 Laukkanen P, Heikkinen E, Kauppinen M. Muscle strength and mobility as predictors of survival in 75-84-year-old people. Age Ageing 1995;24:468-73.

18 Katzmarzyk PT, Craig CL. Musculoskeletal fitness and risk of mortality. Med Sci Sports Exerc 2002;34:740-4.

19 Metter EJ, Talbot LA, Schrager M, Conwit R. Skeletal muscle strength a a predictor of all-cause mortality in healthy men. J Gerontol A Biol SC Med Sci 2002;57:B359-65.

20 Gale CR, Martyn CN, Cooper C, Sayer AA. Grip strength, body composition, and mortality. Int J Epidemiol 2007;36:228-35

21 Sasaki H, Kasagi F, Yamada M, Fujita S. Grip strength predicts causespecific mortality in middle-aged and elderly persons. Am J Med 2007;120:337-42.

22 Al Snih S, Markides KS, Ray L, Ostir GV, Goodwin JS. Handgrip strength and mortality in older Mexican Americans. J Am Geriatr Soc 2002;50:1250-6.

23 Rantanen T, Volpato S, Ferrucci L, Heikkinen E, Fried LP, Guralnik JM. Handgrip strength and cause-specific and total mortality in older disabled women: exploring the mechanism. J Am Geriatr Soc 2003;51:636-41.

24 Rantanen T, Harris T, Leveille SG, Visser M, Foley D, Masaki K, et al. Muscle strength and body mass index as long-term predictors of mortality in initially healthy men. J Gerontol A Biol Sci Med Sci 2000;55:M168-73.

25 Newman AB, Kupelian V, Visser M, Simonsick EM, Goodpaster BH, Kritchevsky SB, et al. Strength, but not muscle mass, is associated with mortality in the health, aging and body composition study cohort. Gerontol A Biol Sci Med Sci 2006;61:72-7.

26 Swallow EB, Reyes D, Hopkinson NS, Man WD, Porcher R, Cetti EJ, et al. Quadriceps strength predicts mortality in patients with moderate to severe chronic obstructive pulmonary disease. Thorax 2007;62:115-20.

27 Rantanen T, Era P, Heikkinen E. Physical activity and the changes in maximal isometric strength in men and women from the age of 75 to 80 years. J Am Geriatr Soc 1997;45:1439-45.

28 FitzGerald SJ, Barlow CE, Kampert JB, Morrow JR, Jackson AW, Blair SN. Muscular fitness and all-cause mortality: prospective observations. Phys Act Health 2004;1:7-18.

29 Gibbons LW, Mitchell TL, Wei M, Blair SN, Cooper KH. Maximal exercise test as a predictor of risk for mortality from coronary heart disease in asymptomatic men. Am / Cardiol 2000;86:53-8.

30 Stampfer MJ, Willett WC, Speizer FE, Dysert DC, Lipnick R, Rosner B, et al. Test of the National Death Index. Am J Epidemio 1984:119:837-9.

31 Jurca R, Lamonte MJ, Barlow CE, Kampert JB, Church TS, Blair SN. Association of muscular strength with incidence of metabolic syndrome in men. Med Sci Sports Exerc 2005;37:1849-55.

32 Jurca R, Lamonte MJ, Church TS, Earnest CP, Fitzgerald SJ, Barlow CE, et al. Associations of muscle strength and fitness with metabolic syndrome in men. Med Sci Sports Exerc 2004;36:1301-7.

33 Pickering TG, Hall JE, Appel LJ, Falkner BE, Graves J, Hill MN, et al. Recommendations for blood pressure measurement in humans and experimental animals: part 1: blood pressure measurement in humans: a statement for professionals from the Subcommittee of Professional and Public Education of the American Heart Association 
Council on High Blood Pressure Research. Circulation 2005;111:697-716.

34 Balke B, Ware RW. An experimental study of physical fitness of air force personnel. US Armed Forces Med J 1959;10:675-88.

35 Pollock ML, Bohannon RL, Cooper KH, Ayres JJ, Ward A, White SR, et al. A comparative analysis of four protocols for maximal treadmill stress testing. Am Heart J 1976;92:39-46.

36 American College of Sports Medicine. ACSM's guidelines for exercise testing and prescription, 7th ed. Philadelphia: Lippincott Williams and Wilkins, 2005.

37 Sui X, LaMonte MJ, Blair SN. Cardiorespiratory fitness as a predictor of nonfatal cardiovascular events in asymptomatic women and men. $A m$ J Epidemiol 2007;165:1413-23.

38 Sui X, LaMonte MJ, Blair SN. Cardiorespiratory fitness and risk of nonfatal cardiovascular disease in women and men with hypertension. Am J Hypertens 2007;20:608-15.

39 Blair SN, Kampert JB, Kohl HW 3rd, Barlow CE, Macera CA, Paffenbarger RS Jr, et al. Influences of cardiorespiratory fitness and other precursors on cardiovascular disease and all-cause mortality in men and women. JAMA 1996;276:205-10.

40 Lee CD, Blair SN, Jackson AS. Cardiorespiratory fitness, body composition, and all-cause and cardiovascular disease mortality in men. Am J Clin Nutr 1999;69:373-80.

41 Wei M, Kampert JB, Barlow CE, Nichaman MZ, Gibbons LW, Paffenbarger RS Jr, et al. Relationship between low cardiorespiratory fitness and mortality in normal-weight, overweight, and obese men. JAMA 1999;282:1547-53.

42 Fleg JL, Morrell CH, Bos AG, Brant LJ, Talbot LA, Wright JG, et al. Accelerated longitudinal decline of aerobic capacity in healthy older adults. Circulation 2005;112:674-82.

43 Hughes VA, Frontera WR, Wood M, Evans WJ, Dallal GE, Roubenoff R, et al. Longitudinal muscle strength changes in older adults: influence of muscle mass, physical activity, and health.J Gerontol ABiol SciMed Sci 2001;56:B209-17.

44 Ruiz-Ruiz J, Mesa JL, Gutierrez A, Castillo MJ. Hand size influences optimal grip span in women but not in men. J Hand Surg [Am] 2002;27:897-901.

45 Ruiz JR, Espana-Romero V, Ortega FB, Sjöström M, Castillo MJ, Gutierrez A. Hand span influences optimal grip span in male and female teenagers. J Hand Surg [Am] 2006;31:1367-72.

46 Espana-Romero V, Artero EG, Santaliestra-Pasias AM, Gutierrez A, Castillo MJ, Ruiz JR. Hand span influences optimal grip span in boys and girls aged 6 to 12 years. J Hand Surg [Am] 2008;33:378-84.

47 Rantanen T, Era P, Kauppinen M, Heikkinen E. Maximal isometric muscle strength and socio-economic status, health and physical activity in 75-year-old persons. J Aging Phys Activity 1994;2:206-20.

48 Thomis MA, Beunen GP, Maes HH, Blimkie C), Van Leemputte M, Claessens AL, et al. Strength training: importance of genetic factors. Med Sci Sports Exerc 1998;30:724-31.

49 Ogden CL, Carroll MD, Curtin LR, McDowell MA, Tabak CJ, Flegal KM. Prevalence of overweight and obesity in the United States, 19992004. JAMA 2006;295:1549-55.

50 Alley DE, Chang VW. The changing relationship of obesity and disability, 1988-2004. JAMA 2007;298:2020-7.

51 Calle EE, Thun MJ, Petrelli JM, Rodriguez C, Heath CW Jr. Body-mass index and mortality in a prospective cohort of US adults. N Engl J Med 1999;341:1097-105.

52 Baik I, Ascherio A, Rimm EB, Giovannucci E, Spiegelman D, Stampfer MJ, et al. Adiposity and mortality in men. Am J Epidemiol 2000;152:264-71.

Accepted: 16 June 2008 